\title{
Sizing of district heating systems based on smart meter data: Quantifying the aggregated domestic energy demand and demand diversity in the UK
}

\begin{abstract}
The sizing of district energy systems involves a trade-off between reliability and continuity of service, and avoidance of capital and running costs associated with oversizing. Finding the most appropriate sizing requires a thorough understanding of energy demand. However, empirical data necessary to support such an understanding is scarce, and district energy systems are typically oversized. This study uses smart meter data from the largest field trial to analyse residential energy consumption in the UK. It presents graphically the seasonal and daily variations in energy consumption patterns, the weather dependence of energy loads, and peak hourly demand during particularly cold weather conditions. It also explores the diversity effect in residential energy consumption and computes the after diversity maximum demand at different levels of aggregations. Results show that, peak hourly gas consumption was nearly seven times higher than electricity consumption during the cold spells, while diversity reduced gas and electricity maximum demand per dwelling up to $33 \%$ and $47 \%$, respectively. This empirical quantitative analysis of energy demand and diversity can support improved design and operation of district energy, and in particular, enable reduced capital and running costs, and an improved understanding of economies of scale for district heating networks.
\end{abstract}

Keywords: district energy; load profile; smart meter; demand diversity.

\section{Highlights:}

- Smart meter data monitored in two unusually cold years were analysed.

- Electricity, gas and temperature profiles over a whole year were constructed.

- Power temperature gradients were demonstrated based on the external temperatures.

- Winter peak hourly gas to electricity consumption ratio was around seven.

- After diversity maximum demand for gas and electricity were illustrated. 


\section{Introduction}

Demand for heat makes up the largest proportion of both annual and peak hourly energy demands in the UK [1]. Due to well-developed natural gas networks and cheap natural gas, gas boilers are the main heating technology in more than $85 \%$ of British households [2]. In order to achieve net-zero greenhouse gas emissions by 2050, the Committee on Climate Change [3] suggested that near-full decarbonisation of heat for buildings would be one of the greatest challenges. $[4,5]$ proposed that district heating networks and electric heat pumps together with the decarbonised electricity grid could play a central role in the UK's future approach to heating. In order to appropriately design and economically implement district heating networks and thereby replace the existing gas boilers, a thorough understanding of heat demand from dwellings based on empirically data is imperative.

Quantifications of heat consumption and peak demand are the essential factors relating to the size of installed capacities of heat generation, transmission pipes and substations of district heating networks. They can be used to ensure that installed generation capacities are able to meet the maximum heat demand, as well as any unpredictable demand increases, alongside improved utilisation. Nevertheless, there is a lack of empirical investigations regarding the diversity effect of energy consumption at an aggregated level in the UK, and very few studies have investigated domestic heat load profiles or their aggregation.

Energy load profiles can illustrate how energy is consumed over time, and can be aggregated according to different spatial and temporal scales as the results of interactions between various sub-systems. Individual households can, for a number of reasons, have very different energy demand patterns, and not all customers will likely demand their peak energy use at precisely the same time. Consequently, when individual households are combined into a group at an aggregated level, the maximum demand arising from a group of households is less than the sum of individual maximum demands due to diversity, the reason being that individual demand peaks are unlikely to occur simultaneously. Hence, the maximum demand per household declines when more households are added to a given system.

The term 'demand diversity' is used to describe this phenomenon, which is a key determinant of capital costs and economies of scale for all energy vectors, and of distribution losses in heat networks. Also, demand diversity can be applied to evaluate investments, design contracts and tariffs, regulate energy generation and purchasing, and develop and validate energy models. For example, results from peak heat demand and diversity studies allow heat supplying utilities to prepare for peak loads and purchase equipment that has a rated generation capacity that is less than the sum of all the individual peak demands from all the individual consumers.

In heat supply industries, the 'rule of thumb' approach is commonly used to assess heat loads and demand diversity, and often according to the number of customers, floor areas, and/or set temperatures [6]. Installers who are trained to design boiler-based systems often deliberately oversize heating systems and use this as an insurance against inadvertent under-sizing [6]. However, the heat network Code of Practice for the UK [7] specified that peak demand should be determined by monitoring the heat currently supplied to the building or its fuel use, using meters and recording data at hourly or half-hourly intervals. They also emphasised that a full year's data would be very valuable and needs to include monitoring of external air temperatures. Nevertheless, [8] pointed out that the monitored hourly profile of single users' heat demand is commonly unknown. 
It is difficult to predict instantaneous heat demand, as it emerges from complex interactions between building envelopes, heating systems, weather conditions, and occupants' behaviour. Fundamentally, the phenomenon is a sociotechnical one $[9,10]$. Also, heat demand is rarely measured directly. Where it is available, gas consumption data can be used, with caveats, as a proxy for heat demand. Furthermore, monitored energy data are commonly kept confidential for commercial or privacy reasons, or are greatly aggregated at the level of national or regional statistics, with restricted metadata. Therefore, due to the lack of heat meters and the restricted availability of smart meter data from the UK's domestic buildings on a large scale, there are gaps in previous studies related to empirical investigations of high-resolution heat load profiles, and regarding the phenomenon of diversity of heat demand in different types of dwellings across a large sample size.

Understanding energy demand heterogeneity arising from end-users and technical systems in buildings is fundamental for evaluating energy supplying technologies, and for designing costeffective strategies to meet demand. This study obtained monitored individual households' electricity and gas consumption data with metadata from the larget smart meter field trial in the UK, and utilised gas consumption data as a proxy to offer insight into heat demand and diversity in residential buildings. This paper graphically quantifies and compares seasonal and daily variances in residential gas and electricity consumption patterns throughout a consecutive year, appraises the weather dependence of electricity and gas loads, and highlights peak hourly energy consumption on the coldest days. It is the first study to explore the diversity effect in residential energy consumption quantitatively based on real consumption data in one of the coldest winters in the UK over the last four decades. Results from this study offer a better understanding of economies of scale for district heating networks, and can be applied, with caution, to determine the size of district heating generation, transmission, and distribution systems, particularly in forecasting heat demand, designing economic grid operations, to ensure district heating infrastructure reliability while reducing capital costs and the risks of over- or under-sizing and interruptions to services.

\section{Literature review: Energy load profiles and energy demand diversity}

The diverse variations in energy consumption behaviours from individual residents will determine the aggregated energy demand characteristics, according to different seasons and times of day. Studies have demonstrated that aggregated electricity load profiles can provide seasonal and intra-daily characteristics of consumption patterns in different types of households $[11,12]$, and can be applied to load management based on different levels of temporal aggregation [13]. Load predictions have been recognised as crucial input parameters for planning mixed energy distribution systems [14].

Annual load duration curves, daily or hourly peak- and off-peak load profiles are required for modern district energy transmission and distribution systems, particularly in load forecasting, to ensure reliability while reducing the risks of inappropriate sizing, and interruptions in services [15]. Multiple studies of energy supply security find strong surges in aggregated energy use and peak demand during certain parts of the year, in response to seasonal weather changes in different countries [16-19]. Recently, [20] studied Britain's aggregated hourly gas demand and electricity supply during a cold weather event in March 2018, and indicated that from 5:00 to 8:00, the gas demand increased by $116 \mathrm{GW}$ (from $89 \mathrm{GW}$ to $205 \mathrm{GW}$ ). They highlighted that studying peak heat demand through empirical data could be critical to the security management of the energy system during extreme weather events. 
There is ample literature on residential electricity load profile modelling in the UK [21, 22]. For example, [23] modelled the socioeconomic diversity and scaling effects on the UK's domestic electricity load profiles, using differentiated dwelling archetypes for English and Welsh neighbourhoods. They found that temporal variations in electricity loads were considerably affected by household socioeconomic characteristics at the neighbourhood level. Moreover, [24] examined electricity demand models and time use data from a group of European countries, including the UK. These studies also emphasised the significance of future monitoring studies based on actual end-users' smart metering data.

Although much research has studied electricity load profiles for British residential buildings using empirical data [25-28], there have been few studies of heat load profiles using actual energy consumption data from large samples. Previously, [29] developed a simple method for simulating the daily heat load profile in the UK's domestic buildings. Moreover, [30] analysed energy consumption data from smart meters and explored 24-hour delivered power profiles to categorise dwelling energy performance and quantify energy savings from retrofitting. Nevertheless, perhaps reflecting the historical dominance of gas and electric heating, there is little detailed published information on monitored hourly heat loads profiles for the UK's individual dwellings. Such load profile studies that have been published have relied on theoretical modelling or small samples, which do not support a thorough understanding of the stochastic nature of demand and its aggregation on a large scale.

Studies have been conducted to calculate and predict domestic electricity load diversity since the 1930s [31]. The diversity factor was introduced as an index that offers insight regarding the probability that one household will consume energy coincidentally to another. It is defined in Equation (1) as: "the ratio of the sum of the individual non-coincident maximum demands of various subdivisions of the system to the maximum demand of the complete system" [32]. It measures the extent to which load profiles for individual loads interleave, with the peak(s) in the $\mathrm{n}^{\text {th }}$ load falling to a greater or lesser extent into the trough(s) in the aggregate of the preceding n-1 loads. The diversity factor is never less than one. The higher the diversity factor, the lower the probability that the energy demands of households will peak simultaneously. Some studies use the term 'coincident factor' or 'coincidence', which is the reciprocal of the diversity factor, as shown in Equation (2), and it has a value between zero and one.

$$
\begin{gathered}
\text { Diversity factor }=\frac{\sum \text { Individual maximum demand }}{\text { maximum demand of the aggregated system }} \\
\text { Coincident factor }=\frac{1}{\text { Diversity factor }}
\end{gathered}
$$

The after diversity maximum demand (ADMD) considers diversity between customers, and has been used to design electricity distribution systems where demand is aggregated across a group of customers [33-35]. It represents the diversified peak demand per customer with respect to the number of customers connected to the network. As shown in Equation (3), the ADMD is calculated as the simultaneous maximum demand within a group of dwellings $\left(M D_{i}\right)$, divided by the number of dwellings (N). The ADMD per customer decreases due to the diversity effect when the number of customers connected to the network increases, and becomes stable when the number of customers approaches infinity. Nonetheless, the ADMD is not necessarily a monotonically decreasing function of the number of customers in the system [36]. 


$$
A D M D=\lim _{N \rightarrow \infty} \frac{1}{N} \sum_{i=1}^{N} M D_{i}
$$

The ADMD can be used to determine the sizing of any energy supply or conversion system, including electrical wires or district heating pipes and substations. [37] suggested that a homogenous group of more than 100 customers to be sufficient for estimating an accurate ADMD value for electricity distribution. However, there is a lack of literature concerning the number of customers needed to accurately assess the ADMD for heat distribution based on empirical evidence.

Previously, different methods have been used to model electricity ADMD for forecasting maximum electricity demand on district energy networks, such as Monte Carlo simulations [38, 39]. Some studies have had high resolutions to simulate multi-energy demand profiles in the UK [21, 40]. [22] and [41] developed models to compare synthesised electricity demand profiles and ADMD with measured data in dwellings and substations. Both studies demonstrated the value of studying electricity profiles and diversity for planning local electricity distribution networks, to forecast future demand, and integrate future technologies. Furthermore, [42] studied mixed modelled and monitored residential electricity load profiles in order to inspect ADMD variations, based on different sampling periods and aggregation scales of up to 60 homes. They concluded that the variance of electricity load decreased as the sampling resolution was reduced and aggregation level increased. Nevertheless, modelling studies face challenges in terms of capturing the stochastic nature of energy consumption across a large number of households.

Some studies have attempted to measure and describe electricity demand diversity through empirical data, but more evidence-based studies are needed to assess diversity in domestic heat demand. [34] and [43] computed domestic electricity ADMD according to different demographic groups using smart meter data, and they proposed that the electricity ADMD per dwelling and the uncertainty decrease in general as the number of dwellings increases, with the final ADMD stabilising below $2 \mathrm{~kW}$ per dwelling. [34] also stated trivially that the electricity ADMD was higher in customer groups with higher incomes or electric vehicles. Similarly, [44] found higher energy use in larger dwellings with higher income through analysing monitored hourly temperature and energy consumption in gas centrally heated 'low-energy' dwellings in the UK. Furthermore, [45] studied the ADMD for electric heat pumps using monitored electricity consumption data pertaining to roughly 700 heat pumps in the UK, and found that the ADMD per heat pump decreased by about $57 \%$ from $4 \mathrm{~kW}$ to $1.7 \mathrm{~kW}$, and reached to its final value at 275 heat pumps. Nevertheless, the paper only dealt with the ADMD for electricity demand from electric heat pumps, as opposed to the ADMD for heat demand from households.

Although there is no standard to quantify the diversity factor and ADMD for residential heat demand in the UK, several standards have been introduced to characterise the diversity effect in other countries for different purposes including sizing the heat exchanger capacities, hot water pipes and district heating hot water flow rates [46-49]. Different standards have applied various input factors or assumptions to calculate diversity factors, such as number of occupants, dwellings, or hot water flow rates. The MTA2016 is used in France and suggests that the coincident factor of domestic hot water demand drops from 1.0 to 0.125 when the number of apartments increases from one to 14 [46]. After adapting the Code of Practice for drinking water installations and assuming all residential units are standardised, the DIN 4708 and the DIN 1988-300 are used to calculate residential hot water demand, size district heating pipes and determine the peak flow rates for domestic hot water supplies in Germany [47]. 
Moreover, the Danish Standard DS439 [48] is the most commonly used standard in the district heating sector. It was introduced to size the heat exchanger for domestic hot water supplies based on 'the number of normal apartments', and it has been adopted as the standard diversity curve to design and develop district heating in the UK by the CIBSE's heat network Code of Practice [7]. Meanwhile, the Swedish District Heating Association [49] suggested a heat power diversity curve (the DHA F:101 standard) based on the domestic hot water flow rates (litres per second) and the designed temperatures at the taps for different types of dwellings. Nevertheless, neither the DS439 nor the DHA F:101 considers residential space heating demand.

Additionally, [6] argued that it is uncommon to use an instantaneous heat exchanger to serve a large number of dwellings with domestic hot water only in Denmark, and that the DS439 curve is old, predating the arrival of low-flow water fixtures. [6] also stated that "consultants specify large peak hot water loads for individual dwellings, scales these reference curves, and claim that the resulting designs are 'designed in accordance DS439' or similar. This is untrue - such calculations are their own work not a nationally accepted standard." Furthermore, [50] pointed out that the DS439 has never been formally translated into English, and the diversity effect of heat demand in UK dwellings is not thoroughly understood. Therefore, a standard derived from primary data from a more relevant sample of dwellings is desirable to improve the understanding of the actual residential heat demand diversity in the UK.

A recent updated version of the heat network Code of Practice [51] stated that "if time permits and it is appropriate, peak demands should be determined by monitoring the heat currently supplied to the building or its fuel use, under external design conditions using existing or temporary meters and recording data at hourly or half-hourly intervals." Accurate heat measurements are essential for efficaciously assessing the performance of heating technologies. However, metered heat consumption data are scarcer than metered electricity data in the UK, and sometimes contradictory statistics are reported by different sources [52]. A comprehensive knowledge of actual energy load profiles and quantified demand diversity is essential for efficient and reliable heating system development.

\section{Data and methods}

Energy consumption data from the Energy Demand Research Project (EDRP) smart meter field trials are used in this study to analyse residential energy load profiles and energy demand diversity. The EDRP was a nationwide energy use study involved in 61,344 households, including 18,370 households with smart meters [53]. The EDRP was conducted by four major gas and electricity supply companies (EDF Energy Customers Plc, E.ON UK Plc, Scottish Power Energy Retail Ltd and SSE Energy Supply Ltd) across Britain between 2007 and 2010, and the datasets were made publicly available [53]. The first generation of smart meters (Smart Meter Equipment Technical Specification, also known as SMETS1) were installed at individual dwellings with real-time display devices which show energy consumption. Raw data were centrally collected from the four companies by the Centre for Sustainable Energy (CSE), and an independent review of the field trials were conducted by [53].

Furthermore, during the EDRP field trials, the UK experienced two remarkably cold winters. According to meteorological records, winter 2008/2009 was the coldest winter since 1996/1997 [54], and the widespread and prolonged cold spells made winter 2009/2010 the coldest winter since 1978/1979 [55], and the seventh coldest winter since 1910 in the UK [56]. This provides 
opportunities to study energy load profiles and peak demand during particularly cold weather events.

This study gathered monitored half-hourly gas and electricity consumption data from 18,370 dwellings, plus a subset from one of the four participating companies, EDF Energy, which offers detailed household metadata from 1,879 dwellings in England. For the absence of heat meters, and where gas boilers were the most popular heating measures in the UK [57], this study uses natural gas consumption data as a proxy for representing heat demand. Energy consumption data were extracted, resampled, and analysed to explore energy load profiles, as well as to study winter peak hourly demand and ADMD in 2009. The whole EDRP dataset was used to investigate the aggregated loads based on different temporal sampling intervals, and time series energy consumption data from individual dwellings with detailed metadata were averaged according to five types and age groups of dwellings to calculate the aggregated dwelling loads and annual consumption per dwelling. Furthermore, half-hourly smart meter data were resampled into hourly data in order to link with the hourly external temperature data for the studied dwellings. Figure 1 provides an overview of the datasets used for this study and a summary of data selection and analysis procedures.

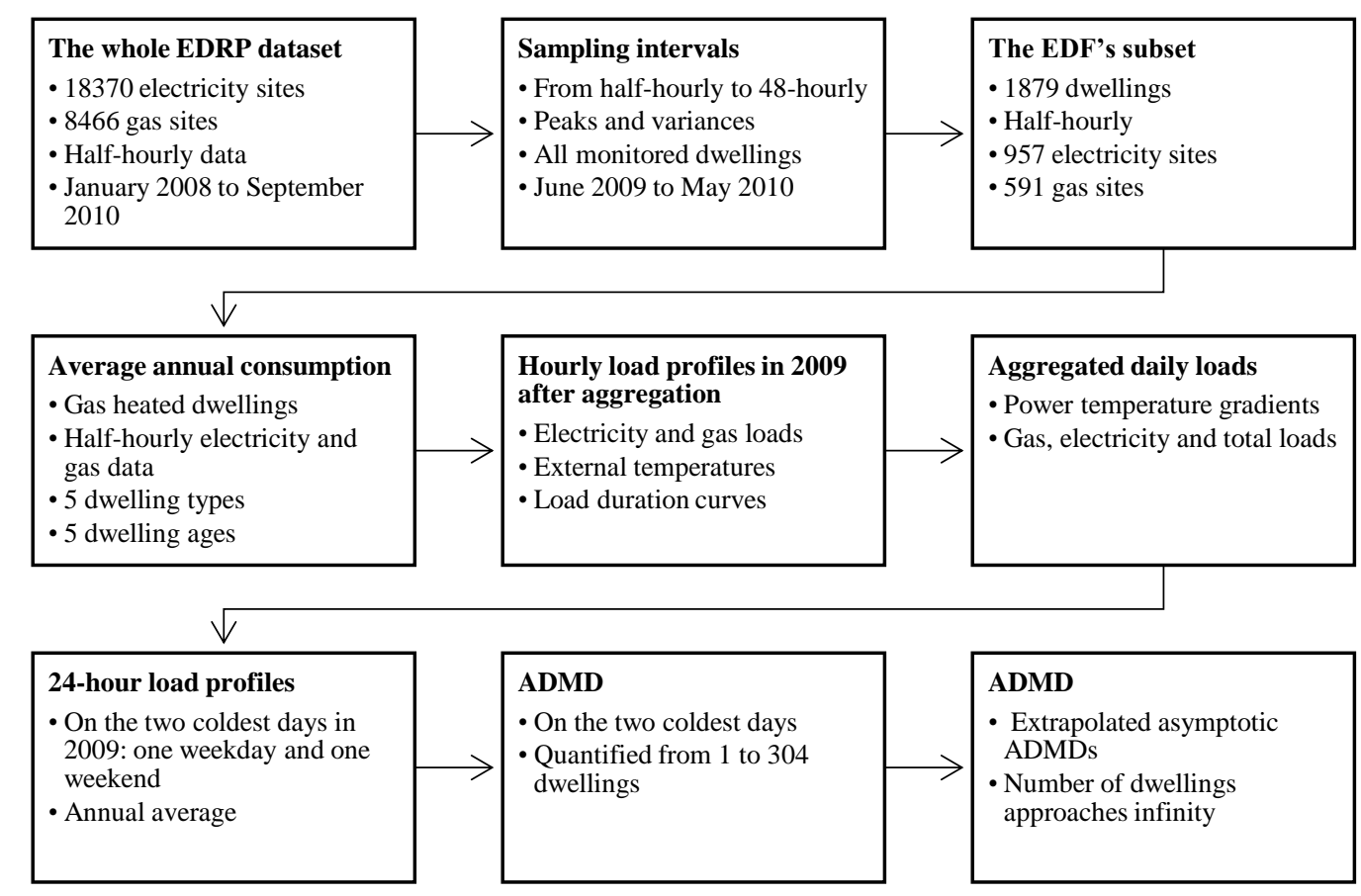

Figure 1. An overview of data selection and analysis stages.

This study aims to study not only energy consumption, but also the causal drivers and mechanisms behind the differences in aggregated peak energy demand when the number of dwelling increases. The whole EDRP dataset with 18,370 dwellings was used to calculate the peak and average annual electricity and gas consumption per dwelling. Because households have different heating measures and monitoring periods, this study focuses on the EDF Energy's subset of dwellings for which high quality monitored energy consumption data and metadata was available on dwelling types, ages and main heating technologies. Following data selection and extraction processes under four conditions, smart meter data from 304 out of 591 households were obtained. First, there were metadata related to the types and ages of dwellings; second, the selected dwellings' monitoring periods included the entire year of 2009; third, both 
electricity and gas were monitored on a half-hourly basis; finally, selected households used gas boilers as the main heating systems to meet their domestic heat demands.

After energy consumption data from 304 dwellings were extracted, hourly external temperature data from [58] were assembled for the sampled individual dwellings, based on their postcodes, and at a resolution of approximately $4 \mathrm{~km}$ (0.04 degrees). Energy consumption throughout 2009 was calculated according to the different types and ages of dwellings. Then, the selected electricity and gas consumption data were resampled and aggregated across all dwellings to construct the hourly electricity and gas load profiles, in order to match hourly external temperatures. The two coldest days (one weekday, and one weekend) were identified based on both daily average and hourly minimum external temperatures; 24-hour load profiles were constructed to study the shapes of hourly load profiles on the two coldest days. Meanwhile, the aggregated daily electricity and gas consumptions were plotted against the aggregated daily external temperatures to study changes in energy demand in response to changes in external temperatures.

The diversified hourly maximum electricity and gas demand (ADMD) per dwelling and how they changed when the number of households increased in one network, was further analysed for the two coldest days in 2009, according to Equation (3). A random sampling approach was applied to selected dwellings, with ADMD re-calculated after addition of each dwelling, from one to 304 (293 for gas ADMD on Saturday due to missing data from 11 dwellings). This process was repeated for 50 trials on each day to examine the mean of ADMD. Then, the results from 304 dwellings were extrapolated to estimate electricity and gas ADMDs per dwelling when the number of dwellings approaches infinity.

\section{Results and discussion}

To understand how much and when energy is consumed is fundamental to evaluating supplying technologies and designing cost-effective strategies to meet energy demand. This section illustrates and discusses the results of smart meter data analyses and their applications on district heating designing. It first quantifies and compares annual energy consumption in typical types of dwellings in the UK through monitored smart meter data. It investigates seasonal and daily variances in residential gas and electricity consumption patterns throughout a consecutive year, appraises the weather dependence of electricity and gas loads, and highlights peak hourly energy consumption under rare cold weather conditions. It then explores the diversity effect in residential energy consumption and computes the ADMD, to support the improved design of district heating systems.

\subsection{Sampling intervals and their impact on peak energy loads}

Because temporal sampling frequency is an important feature which could affect the peak energy demand [13], a series of sampling time intervals, from half-hourly to 48-hourly, were applied to quantify the peak gas and electricity loads per dwelling. Half-hourly gas and electricity data from $1^{\text {st }}$ June 2009 to $31^{\text {st }}$ May 2010 were analysed to calculate the peak and average gas and electricity consumption per dwelling. The results found that the average annual gas consumption was $17,880 \mathrm{kWh}$ per dwelling (from 8,466 monitored dwellings), which was almost four times higher than the average annual electricity consumption, accounting for 4,490 
$\mathrm{kWh}$ per dwelling (from 18,370 monitored dwellings). Meanwhile, Figure 2 and 3 demonstrate different load profiles over a year and the changes in peak energy loads and the sample variances at an aggregated level when the temporal sampling frequency was changed from halfhourly to longer time intervals. These figures show that the peak energy loads did not change expressively when the sampling time interval increased from half-hourly to hourly. In contrast, when the sampling time interval increased from hourly to 48-hourly, the peak loads dropped considerably.
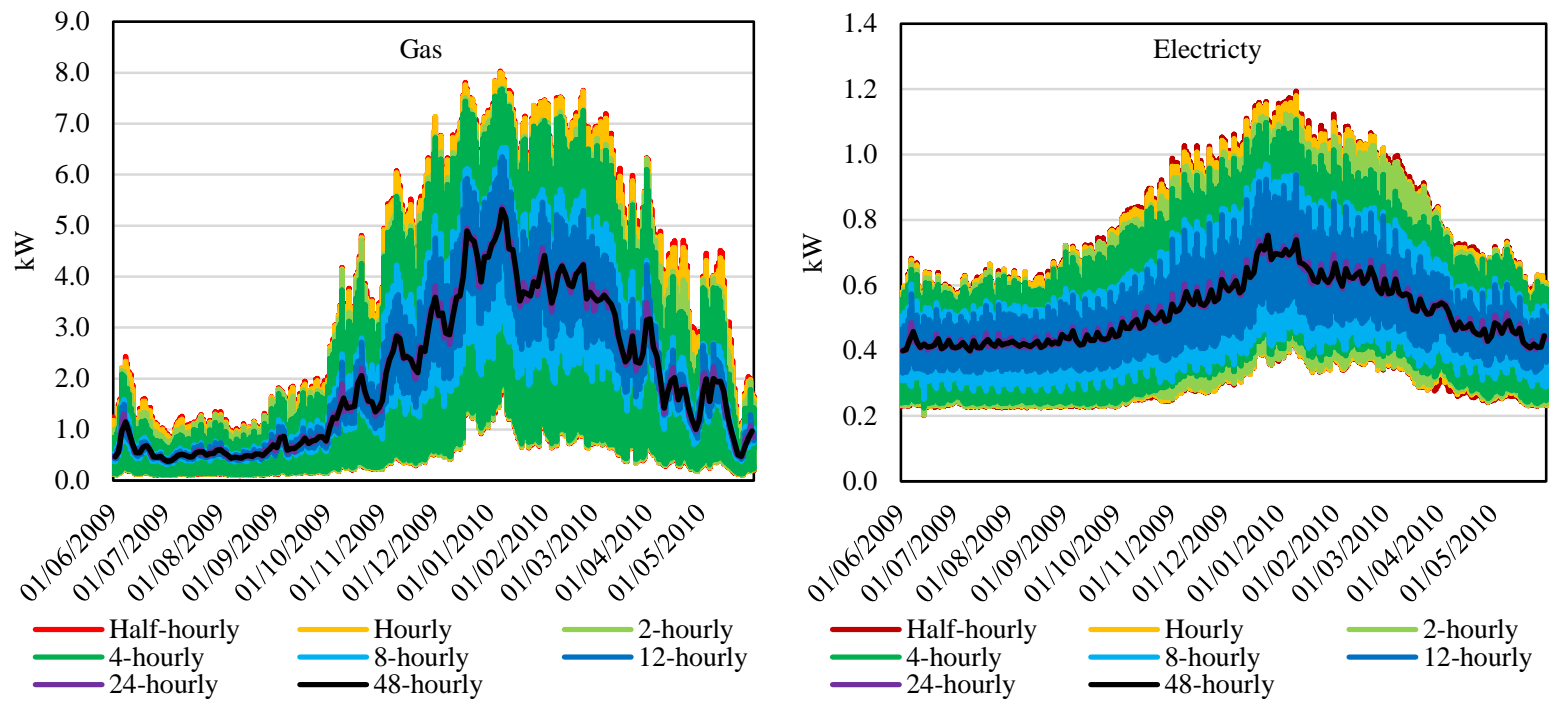

Figure 2. Electricity and gas load profiles based on different temporal sampling frequencies between 1st June 2009 and 31st May 2010.
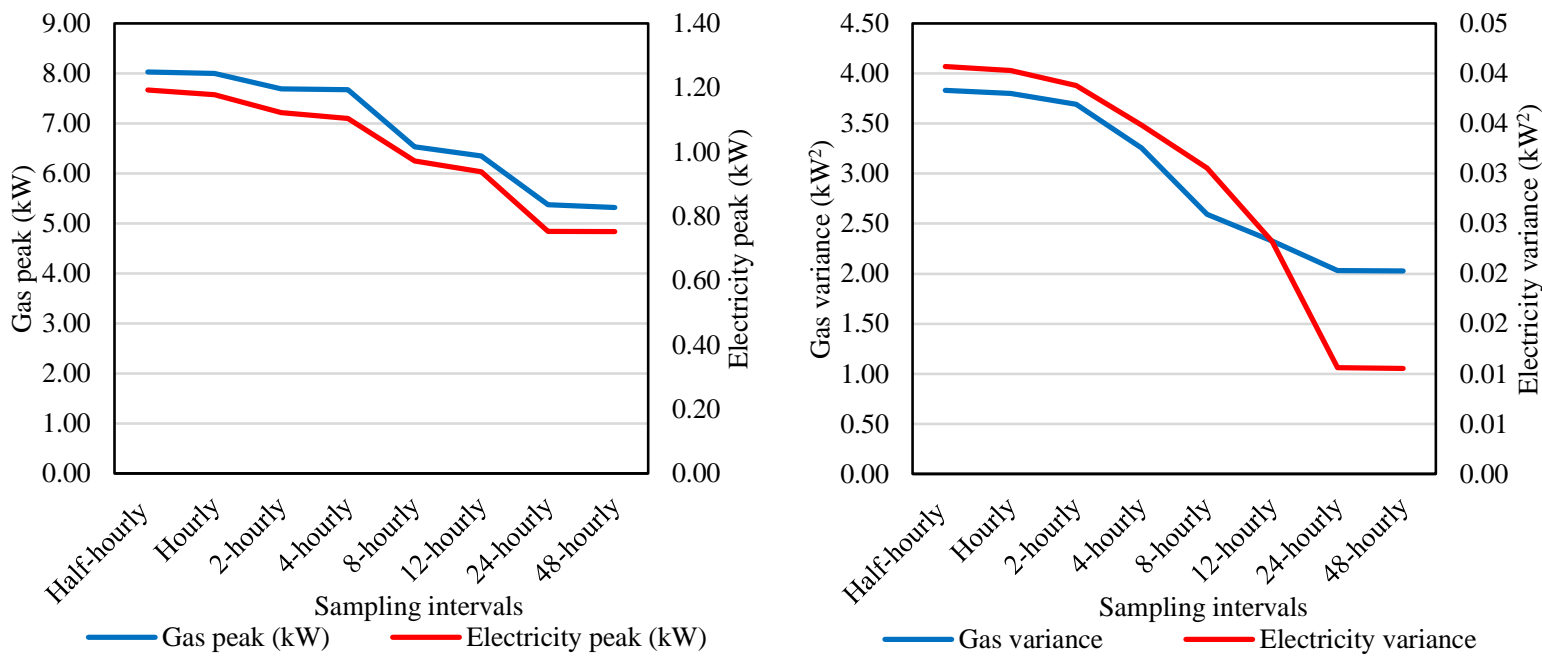

Figure 3. Impact of temporal sampling frequencies on the aggregated peak gas and electricity loads and variances.

As shown in Figure 2 and 3, the monitored half-hourly gas and electricity loads peaked at approximately $8.0 \mathrm{~kW}$ and $1.2 \mathrm{~kW}$ per dwelling in the winter. The peak gas and electricity loads only decreased by $0.4 \%$ and $1.2 \%$ respectively when the sampling time interval increased from half-hourly to hourly. However, the winter peak gas and electricity loads dropped by more than $33 \%$ and $37 \%$ when the sampling interval became longer than 24 hours, and the peak gas and electricity loads reached around $5.3 \mathrm{~kW}$ and $0.8 \mathrm{~kW}$ per dwelling when the sampling time interval was 48-hourly. Furthermore, Figure 3 shows that averaging of energy consumption 
over progressively longer intervals of time progressively reduces the variance. The sample variance decreased by over $47 \%$ (gas) and $74 \%$ (electricity) when the sampling time interval increased from half an hourly to more than 24 hours. Therefore, half-hourly and hourly data are more suitable than data with longer sampling time intervals to study peak energy loads. This study utilises hourly energy consumption data, due to the availability of external temperature data.

\subsection{Annual consumption in different ages and types of dwellings}

Table 1 illustrates the monitored electricity and gas consumption for different ages and types of dwellings in 2009 based on smart meter data and metadata. As expected, the newer the dwelling, the lower the annual gas consumption tends to be, with below $15,000 \mathrm{kWh}$ of gas required in dwellings built after 1980, whereas the annual gas consumption for dwellings built before 1919 was about $23,800 \mathrm{kWh}$. The annual electricity and gas consumption for a detached house was the highest of all dwelling types, accounting for over 5,300 kWh of electricity and $23,000 \mathrm{kWh}$ of gas. This is because of the five main dwelling types in the UK, detached houses lack shared elements such as party walls and tend to be larger. In contrast, a flat consumed only around 3,000 kWh of electricity and less than $13,000 \mathrm{kWh}$ of gas on average.

\begin{tabular}{llllll}
\hline Dwelling age & Before1919 & $\mathbf{1 9 1 9 - 1 9 4 4}$ & $\mathbf{1 9 4 5 - 1 9 6 4}$ & $\mathbf{1 9 6 5 - 1 9 8 0}$ & After1980 \\
\hline Gas (kWh) & 23764 & 21699 & 18745 & 16278 & 14937 \\
Electricity (kWh) & 4821 & 5294 & 4933 & 4199 & 4417 \\
\hline Dwelling type & Detached & Semi-detached & Terraced & Bungalow & Flat \\
\hline Gas (kWh) & 23142 & 18859 & 16909 & 17804 & 12938 \\
Electricity (kWh) & 5306 & 5283 & 4089 & 4304 & 3019 \\
\hline
\end{tabular}

Table 1. Annual gas and electricity consumption in different types and ages of dwellings.

\subsection{Hourly load profiles}

Figure 4 demonstrates the average hourly electricity and gas consumption profiles per dwelling versus the external temperature for the year 2009. The diagram shows that the monitored gas and electricity consumption had clear ties to the changes in the external temperature. It shows the volatile seasonal changes in domestic gas consumption, with most of the demand occurring between November and May. At the aggregated scale, the maximum hourly gas consumption reached more than $9.2 \mathrm{~kW}$ per dwelling during the coldest periods in the year, which is about seven times higher than the winter peak hourly electricity demand (over $1.3 \mathrm{~kW}$ ). In contrast to high winter energy consumption due to high heat demand, the maximum hourly gas consumption was less than $1.5 \mathrm{~kW}$ per dwelling in the summer, and this dropped to below 0.2 $\mathrm{kW}$ per dwelling during summer nights, lower than the electricity consumption for the same period. 
Furthermore, as the diagram shows, the hourly electricity consumption per dwelling in 2009 was steadier than the gas consumption, with evening peaks fluctuating from more than $1.3 \mathrm{~kW}$ in the winter to below $0.7 \mathrm{~kW}$ per dwelling in the summer. Unlike gas consumption peaks during the winter which were mostly triggered by demands for space heating, the electricity consumption peaks during the winter were most likely caused by additional lighting and the use of home appliances. Additionally, Figure 4 does not display apparent increases in electricity consumption caused by the use of electric air conditioning when the external temperature was higher. Unlike countries such as the US with high deployment rate of domestic air conditioning units, and electricity consumed to meet cooling demand could become a significant component of residential energy consumption [59], the market size of electric air conditioning units in the $\mathrm{UK}$ is very low $[4,60]$. According to [2], less than $1 \%$ of final energy is consumed to supply space cooling in British buildings, due to the temperate oceanic climate and rare hot weather conditions in the summer. Therefore, at an aggregated scale, the impact of cooling demand and electricity consumed by air conditioning on the overall electricity consumption is small.

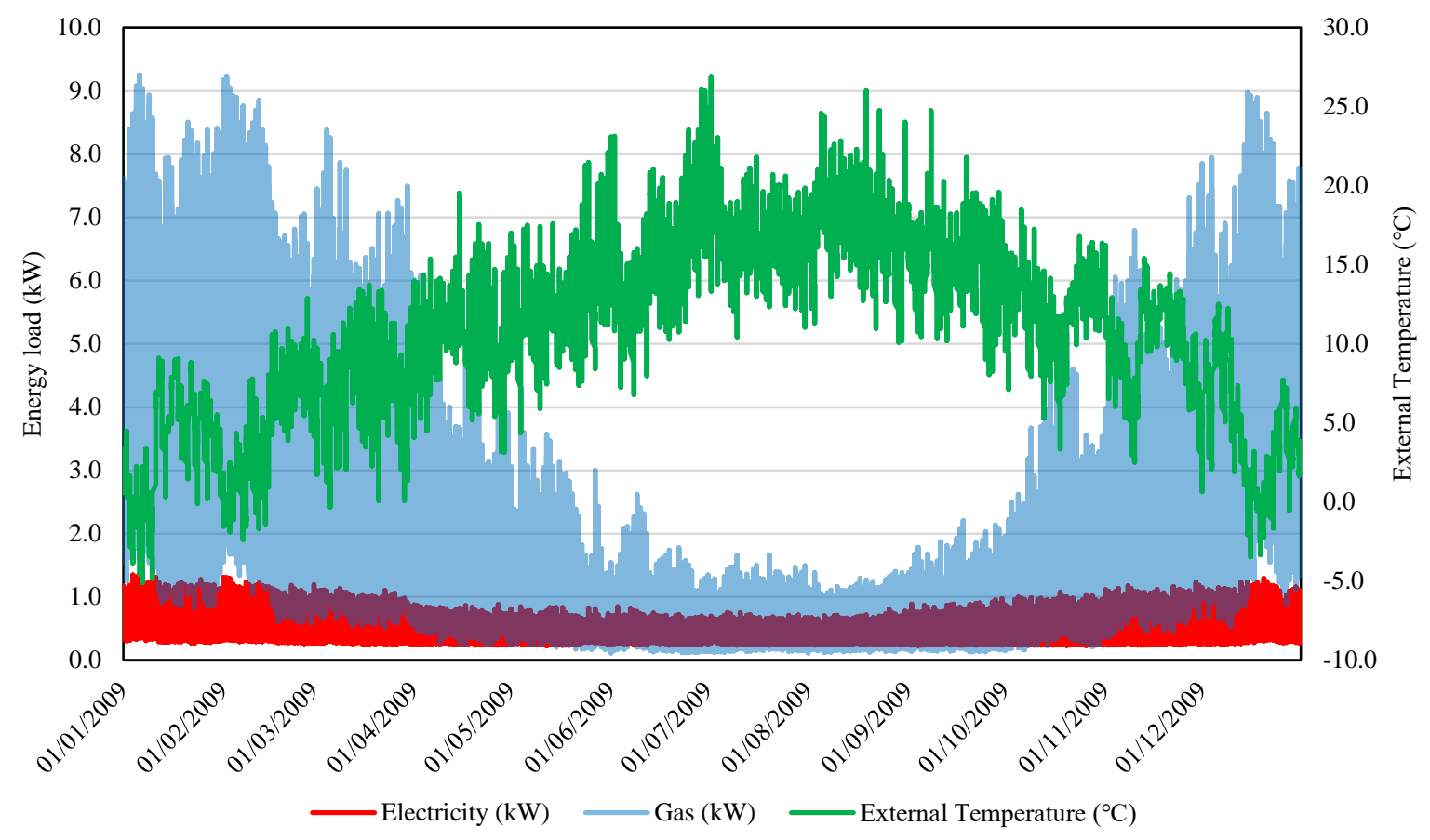

Figure 4. Hourly electricity and gas load profiles versus the external temperature in 2009 .

\subsection{Hourly load duration curves}

As energy consumption fluctuates according to seasonal changes in weather conditions, load duration curves across an entire year are commonly applied in industries for energy generation capacity sizing and cost optimising for multi-source energy co-generations such as combined heat and power plants. The electricity and gas load duration curves were constructed on an hourly basis over 8,760 hours in 2009 from the highest hourly energy consumption to the lowest, as shown in Figure 5. Both electricity and gas load duration curves dropped from their maxima to under $60 \%$ of their peak demands after around 1,000 hours. The aggregated gas load duration curve declined continuously over the year and reached below $50 \%(4.6 \mathrm{~kW})$ of its winter peak after about 1,400 hours, then reached a minimum of $1 \%(0.1 \mathrm{~kW})$. The electricity load duration curve reached below $50 \%(0.7 \mathrm{~kW})$ of its winter peak after about 2,100 hours 
and terminated at $17 \%(0.2 \mathrm{~kW})$. Moreover, the load factors for electricity and gas demands were 0.40 and 0.23 respectively across all sampled dwellings.

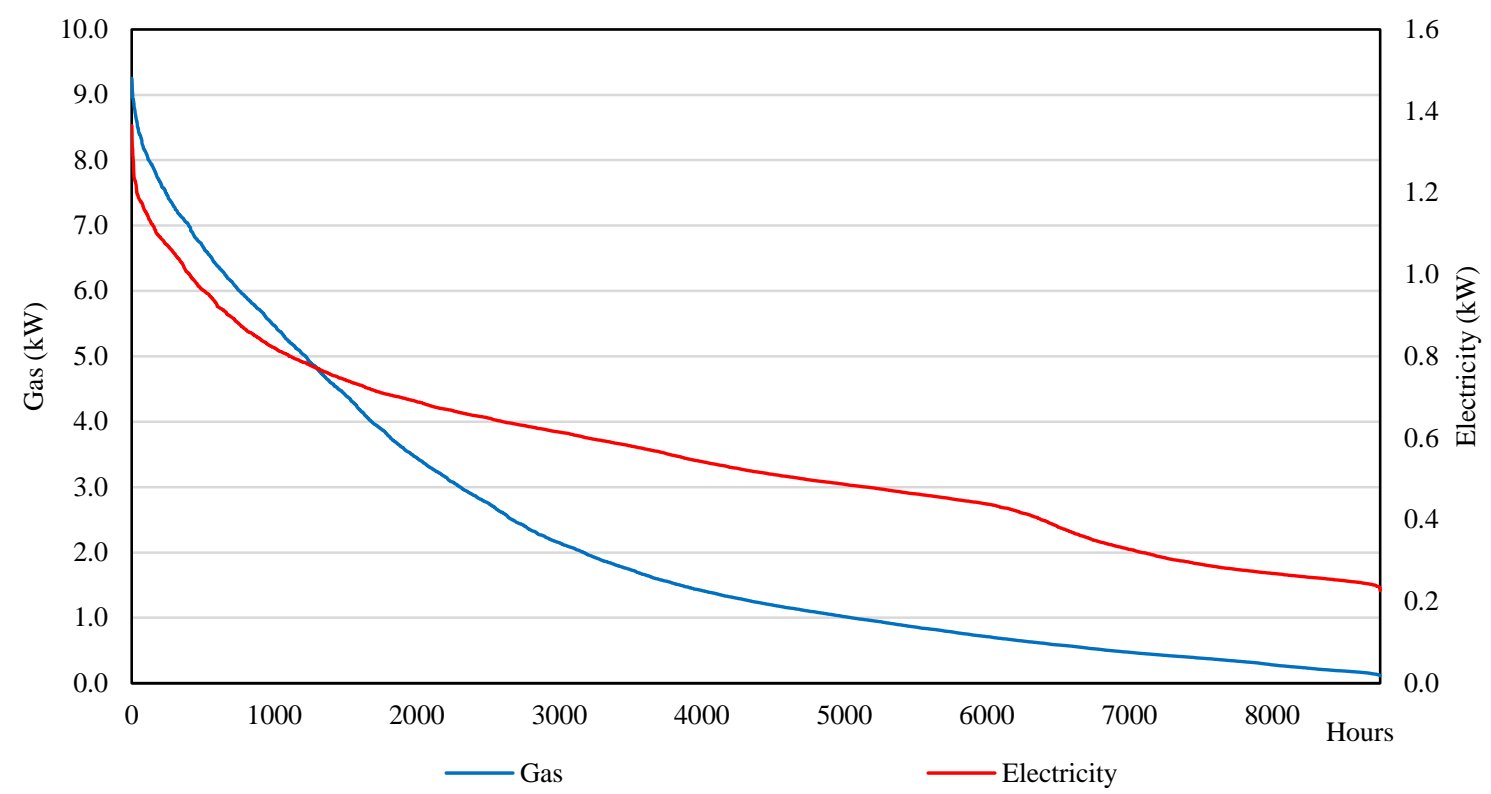

Figure 5. Hourly electricity and gas load duration curves over 8760 hours.

\subsection{Energy consumption and the external temperature correlations}

The energy consumption and external temperature data from the sampled dwellings were averaged into daily values to show the weather dependence of electricity and gas loads as seen in Figure 6, using the same research method applied by [30] which is a useful approach to calculate the linear response in energy demand with respect to external temperature. The slopes in electricity and gas consumption relating to the changes in external temperature (power temperature gradient or power signature) were estimated through linear regression analysis with an upper boundary temperature of $15{ }^{\circ} \mathrm{C}$, accounting for approximately $320 \mathrm{~W} /{ }^{\circ} \mathrm{C}$ for gas and $15 \mathrm{~W} /{ }^{\circ} \mathrm{C}$ for electricity. The diagram provides an empirical indication of domestic energy consumption responding to the external temperatures, and it demonstrates that there are linear interdependencies between energy consumption and the external temperatures up to around $15^{\circ} \mathrm{C}$. Electricity and gas loads were noticeably higher when the external temperature was lower in the range from $-3{ }^{\circ} \mathrm{C}$ to $15{ }^{\circ} \mathrm{C}$. This figure also indicates that electricity consumption was less sensitive to external temperature changes than gas consumption. 

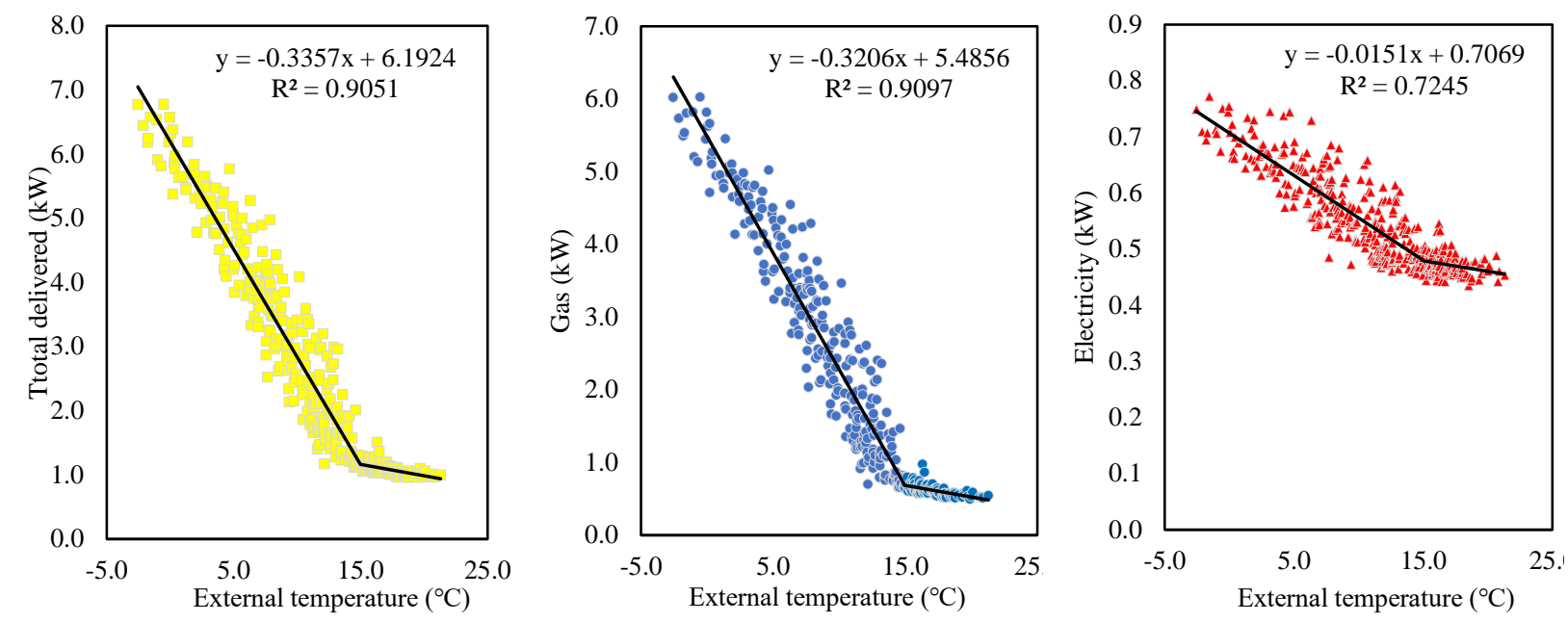

Figure 6. Daily delivered gas and electricity in response to external temperatures.

\subsection{4-hour load profiles on the two coldest days}

After Figures 4 and 6 illustrate that both electricity and gas consumption is higher when the external temperature is lower. In order to investigate the peak energy demand on extremely cold weather conditions, the two coldest days in 2009 were identified as Tuesday $6^{\text {th }}$ January and Saturday $10^{\text {th }}$ January according to the weather records [58]. The aggregated 24-hour hourly energy load profiles were constructed for the two coldest days and compared with the average 24-hour load profiles over a year as shown in Figures 7 and 8.

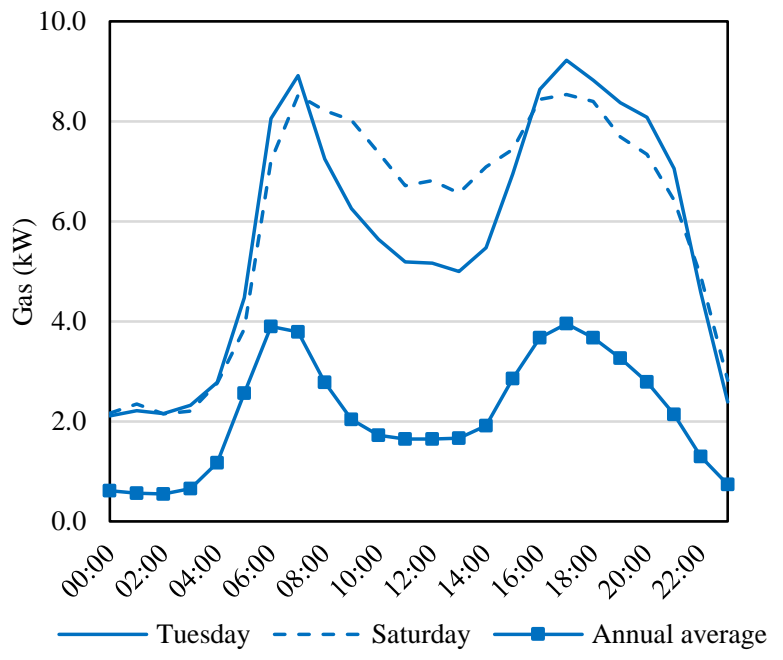

Figure 7. 24-hour gas load profiles on the two coldest days compared to the annual average.

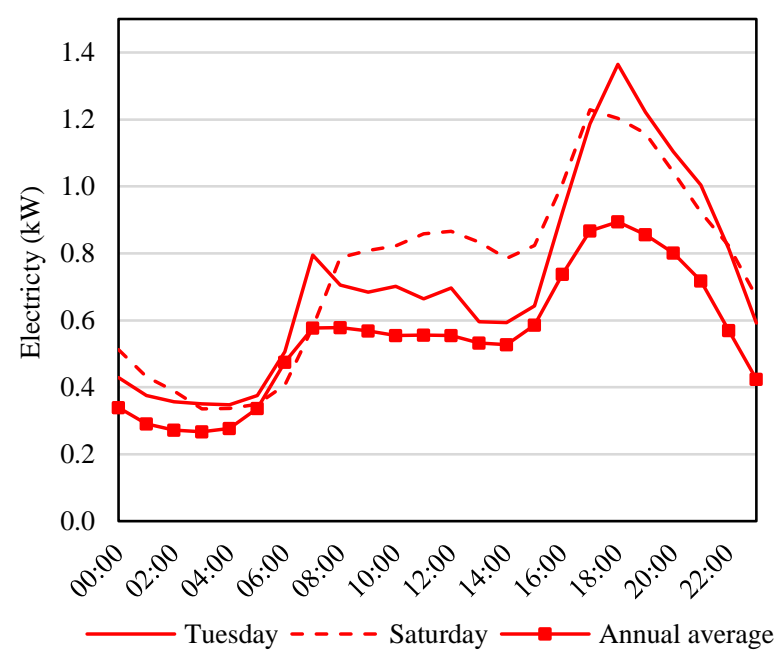

Figure 8. 24-hour electricity load profiles on the two coldest days compared to the annual average.

According to the annual average load profiles, both electricity and gas consumption was very low at night after midnight until around 5:00 and then increased sharply until 8:00, accounting for just below $4.0 \mathrm{~kW}$ per dwelling for gas and $0.6 \mathrm{~kW}$ per dwelling for electricity. Unlike gas load profiles which have two pronounced peaks (around 7:00 and 17:00) and a shallower trough around noon, electricity load profiles show steady consumption until around noon and one distinct peak around 17:00 at about $0.9 \mathrm{~kW}$ per dwelling. 
On the two coldest days, both electricity and gas peaks occurred around 17:00-18:00, but with much higher magnitudes compared to the annual average 24-hour load profiles. On the coldest day of the year, the peak gas and electricity consumption reached more than $9.2 \mathrm{~kW}$ and 1.3 $\mathrm{kW}$ per dwelling, due to higher heat loss from buildings and increased usage of lighting and home appliances. Figures 7 and 8 also show that there was more gas consumption overnight on the two coldest days, while there was no substantial change in electricity consumption. Furthermore, both electricity and gas consumption around noon are higher at weekends than on weekdays, possibly because more dwellings tend to be occupied then, which leads to higher demand for electricity and gas. Additionally, the gas to electricity evening peak ratios were 6.8 and 7.0 respectively on the coldest weekdays and weekends, compared to an annual average of 4.4. In contrast, the morning peak ratios at 7:00 were much higher due to relatively low electricity demand in the morning, accounting for 11.2 (Tuesday), 14.7 (Saturday) and 6.6 (annual average).

\subsection{ADMD on the two coldest days}

The diversity effect and its impacts on the aggregated peak loads were explored for the two coldest days in 2009. The gas and electricity ADMD diagrams in Figure 9 illustrate the changes in peak hourly energy demand per dwelling due to diversity when the number of dwellings in one system increased from one to more than 300 on the two coldest days. Figure 9 indicates that both diversified gas and electricity peak loads per dwelling decreased rapidly first and then stabilised to approach to asymptotes when the number of aggregated dwellings increased. Furthermore, Figure 10 reveals the estimated gas and electricity ADMD per dwelling when the ADMD curves approach to asymptotes. As shown in Figures 9 and 10 and summarised in Table 2 , both final gas and electricity ADMDs were lower on Saturday $10^{\text {th }}$ January than on Tuesday $6^{\text {th }}$ January. With higher diversity factors, the final ADMDs dropped by up to about $33 \%$ for gas and $47 \%$ for electricity from their initial values on Saturday $10^{\text {th }}$ January, whereas the final gas and electricity ADMDs decreased less than $30 \%$ on Tuesday $6^{\text {th }}$ January. 


\begin{tabular}{lllllll}
\hline \multicolumn{3}{l}{ Tuesday 6th January } & \multicolumn{5}{l}{ Saturday 10th January } \\
\hline & $\begin{array}{l}\text { Average ADMD } \\
\text { per dwelling for a } \\
\text { single dwelling }\end{array}$ & $\begin{array}{l}\text { Asymptotic } \\
\text { ADMD per } \\
\text { dwelling }\end{array}$ & $\begin{array}{l}\text { Diversity } \\
\text { factor }\end{array}$ & $\begin{array}{l}\text { Average ADMD } \\
\text { per dwelling for a } \\
\text { single dwelling }\end{array}$ & $\begin{array}{l}\text { Asymptotic } \\
\text { ADMD per } \\
\text { dwelling }\end{array}$ & $\begin{array}{l}\text { Diversity } \\
\text { factor }\end{array}$ \\
\hline Gas & $12.4 \mathrm{~kW}$ & $9.20 \mathrm{~kW}$ & 1.49 & $13.0 \mathrm{~kW}$ & $8.65 \mathrm{~kW}$ & 1.57 \\
\hline Electricity & $1.9 \mathrm{~kW}$ & $1.35 \mathrm{~kW}$ & 1.48 & $2.3 \mathrm{~kW}$ & $1.22 \mathrm{~kW}$ & 1.65
\end{tabular}

Table 2. A summary of ADMD and the diversity factors for gas and electricity on the two coldest days in 2009.

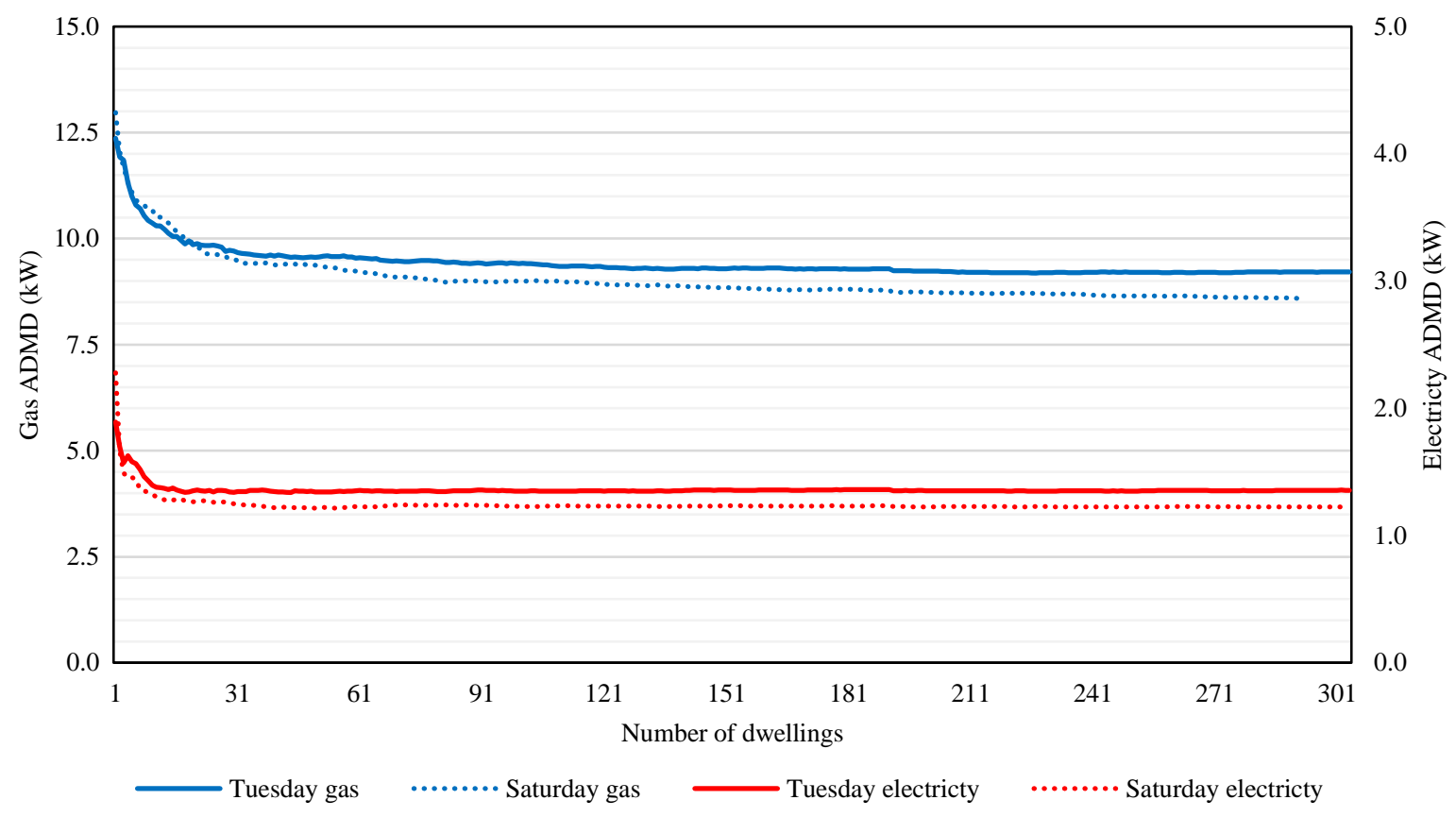

Figure 9. Gas and electricity ADMDs per dwelling on the two coldest days in 2009.

On the coldest weekday in 2009, Figure 9 shows that the gas ADMD stood at just below 12.4 $\mathrm{kW}$ regarding at the first dwelling; then the value dropped rapidly to below $10.0 \mathrm{~kW}(80 \%$ of the initial gas ADMD) per dwelling after aggregating load profiles together for less than 20 dwellings. This continued decreasing to $9.4 \mathrm{~kW}(76 \%)$ after aggregating to 100 dwellings and reached to its final value, to three significant figures, of $9.20 \mathrm{~kW}(74 \%)$ after 190 dwellings. In terms of electricity ADMD, the curves dropped sharply and became relatively flat when only a few dwellings were aggregated together. As indicated on the secondary vertical axis in Figure 9, the electricity ADMD started from about $1.9 \mathrm{~kW}$ at the first dwelling, and then quickly declined to $1.4 \mathrm{~kW}$ ( $74 \%$ of the initial electricity ADMD) per dwelling after only ten dwellings were aggregated. It only took approximately 20 aggregated dwellings for electricity ADMD per dwelling to reach to a final value, with a value of approximately $1.35 \mathrm{~kW}(71 \%)$ per dwelling.

Likewise, the ADMD curves on the coldest weekend had similar shapes to those on the coldest weekday, but with higher starting values and lower final values. In the meantime, more dwellings are needed to estimate the stabilised ADMD on the weekend than on the weekdays. This implies that occupants may have more flexibility to consume energy at weekends. As shown in Figure 9, the gas ADMD dropped rapidly from about $13.0 \mathrm{~kW}$ at the first dwelling to below $10.0 \mathrm{~kW}$ (77\% of the initial gas ADMD) per dwelling after aggregating load profiles 
together for 18 dwellings, and then, stayed below $9.0 \mathrm{~kW}(70 \%)$ after 80 aggregated dwellings. The gas ADMD reached to its final value, accounting for below $8.70 \mathrm{~kW}(67 \%)$ per dwelling after 230 dwellings. Meanwhile, the electricity ADMD per dwelling dropped from around 2.3 $\mathrm{kW}$ to $1.3 \mathrm{~kW}$ when the number of aggregated dwellings increased from one to ten. The electricity ADMD per dwelling remained at $1.22 \mathrm{~kW}$ (53\% of the initial value) from 38 aggregated dwellings.

Figure 9 provides quantitative and empirical evidence that the maximum energy demand of both gas and electricity networks is less than the sum of individual peak demands, and that the maximum demand per dwelling decreases towards an asymptote as more dwellings are added to the network due to the diversity effect. Previous studies [37] suggest that an accurate electricity ADMD could be estimated within a group of 100 homogenous dwellings, and this study found that the electricity ADMD per dwelling remains the same to three significant figures after around 30 dwellings. Nevertheless, this study reveals more than 100 dwellings are needed to estimate the final gas ADMD. Although the rate at which the ADMD per dwelling decreases becomes low after 100 dwellings, it required over 230 dwellings for gas ADMD to remain the same to three significant figures.

Additionally, graphs in Figure 10 illustrate gas and electricity ADMDs per dwelling against $1 /$ number of dwellings (excluding the first 10 dwellings). Linear trendlines are applied in order to extrapolate the number of aggregated dwellings to infinity based on the 304 sampled dwellings, hence to estimate the asymptotic ADMDs per dwelling. As the results show, the final gas and electricity ADMDs on the coldest weekday are estimated as $9.20 \mathrm{~kW}$ and 1.35 $\mathrm{kW}$ per dwelling when the number of dwellings approaches to infinity, and the values drop to $8.65 \mathrm{~kW}$ and $1.22 \mathrm{~kW}$ per dwelling on the coldest weekend due to higher diversity factors.
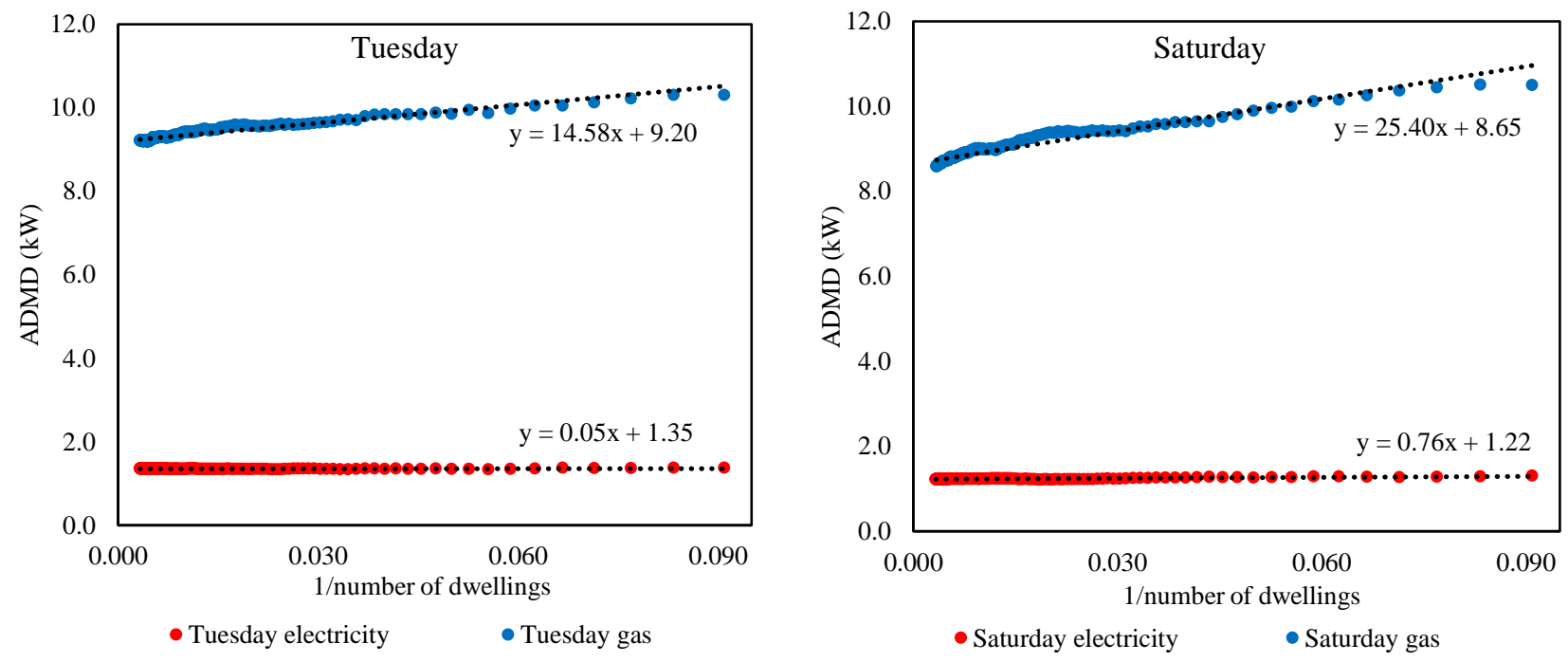

Figure 10. Gas and electricity asymptotic ADMDs per dwelling through extrapolation.

\subsection{Applications of empirical load profiles and demand diversity for designing and sizing energy infrastructures}

Energy consumption correspondingly changes according to the external temperature as Figures 4 and 6 illustrate, and the results from this study agree with previous research and statistics in 
terms of power temperature gradients and annual energy consumption in British dwellings [2, $30,61]$. Although it is challenging to predict future peak energy demand, studying energy consumption during cold weather conditions from empirical data could offer support for the development of energy infrastructures which can ensure energy security in case of future extreme weather events.

The diversity curve from the Danish standard DS439 has been widely used for domestic hot water supply for different numbers of dwellings in district heating networks [7, 51]. However, the DS439 [48] calculated only domestic hot water heating rates based on assumed usage patterns for a normative household, and it admitted that measured energy consumption could help to enable effective and energy-efficient operations. Hence, the DS439 may not be suitable for developing space heating only district heating networks. Furthermore, there is no standard based on empirical diversity studies in the UK which considers both space heating and domestic hot water consumption. Therefore, engineering design becomes defensive to ensure reliability and continuity of service, and common practices tend to oversize the heating system [62].

The consequences of oversizing depend on the technologies involved. Where heating is provided by electricity, resistive losses vary inversely with the capacity of the distribution system, while oversizing reduces distribution losses. Where heating is provided by natural gas, distribution losses are very low, and the oversizing of the gas distribution system is likely to have a minimal effect. In the case of heat networks, heat losses from distribution are roughly proportional to the capacity of the heat distribution system, and the impacts of oversizing may be significant because larger pipes are more expensive and have relatively higher heat loss. Moreover, oversized pipes may contain extra air and debris, which could accelerate the rates of corrosion in pipes.

This study explored the diversified maximum hourly energy demand in 2009, which is one of recent coldest years in the UK. The findings could be advantageous for optimising long-term energy generation as well as managing short-term peak supply and demand and for designing and implementing energy facilities such as district heating networks. For example, although service pipes (tertiary pipes) must be designed based on non-diverse individual maximum heat loads for individual dwellings, distribution and transmission pipes (primary and secondary pipes) could benefit from the diversity effect to forecast maximum heat loads and mitigate the risk of oversizing substations and transport pipes. As ADMD per dwelling decreases when the size of the heat network increases, economies of scale occur to reduce the peak generation and transmission capacities, and therefore, leads to reductions in costs.

In addition, the costs of electricity and gas could affect dwellings' energy consumption and load profiles directly. Due to an abundant natural gas supply and technical developments in gas boilers throughout the 1980s and 1990s, natural gas became the principal fuel source for domestic heating systems in the UK [63]. Under current liberated energy market conditions, typical retail electricity prices are more expensive than retail gas prices, with a common price ratio of approximately 3:1 or higher depending on specific tariffs and regions [64]. This study found that the average annual gas consumption per dwelling was considerably higher than the average electricity consumption. Although it is difficult to forecast future energy prices, it is anticipated that with future projected increase in renewable electricity generation and crossborder market integrations [65, 66], the volatility in energy prices could be intensified and this might lead to variations in individuals' energy consumption patterns and their overall energy demand. 
The UK's industrial strategies have set plans to phase out fossil fuel heating and develop lowcarbon heating technologies such as electric heat pumps and expanded heat networks $[4,57]$. This could transform both gas and electricity load profiles at all levels of aggregation. This study shows that domestic gas consumption is much higher than domestic electricity consumption both in terms of annual demand and hourly peaks, and therefore that if heat demand were solely switched from gas to electricity, the peak electricity loads would be greatly increased [67, 68]. Moreover, the expected future growth of electric vehicles and domestic air conditioning units could further affect domestic electricity load profiles, with consequent need for planning and capacity upgrading, together with demand management and storage to cope with peaks in demand.

This study utilises domestic gas consumption as a proxy for representing heat demand. It does not distinguish demands for space heating and domestic hot water, and this study does not examine heat storages due to the lack of metadata. It is not possible to cleanly separate out cooking loads from space and water heating. The technical characteristics (including nonlinearity) of gas boilers, and the fact that occupants adapt their behaviours to the specific technical characteristics of heating systems and to energy tariffs, mean that patterns of heat demand for gas heated homes, inferred from metered gas data, may differ from patterns of heat demand for homes connected to heat networks, measured with heat meters. This is not ideal, but in the judgement of the authors, is justifiable in the absence of access to heat data for large numbers of dwellings. Previous large field trials and modelling research have revealed that both gas boiler profiles and heat pump load profiles are characterised by a morning and evening peak, however, the profiles differ in detail. Moreover, different types of heat pumps could result in different ADMDs [45, 69, 70]. Future studies could gather metered data from operating heat networks to test the differences between aggregated gas boiler load profiles and district heating load profiles, and the impacts of utilising heat stores on the load profiles.

\section{Conclusions}

Individuals' peak demands and how they are aggregated are crucial factors for determining the size of energy generation, transmission, and distribution systems. Studying end-use energy load profiles and diversity at high temporal resolutions are advantageous when designing load control mechanisms, peak demand management strategies and economic grid operations, as energy supplying and distributing systems can benefit from economies of scale, and reduce capital investment. Nevertheless, there have been fewer empirical studies than modelling studies, because empirical domestic energy consumption data at high temporal resolutions on the large scales can be difficult to access due to technical, ownership and private concerns.

This paper presents an empirical analysis of energy demand using actual end-users' energy consumption data collected from the largest smart meter field trial which included one of the recent coldest years in the UK. Half-hourly smart meter data were employed to explore peak gas and electricity loads based on a range of temporal sampling frequencies. This study summarised annual electricity and gas consumption in different types and ages of dwellings in the UK and investigated the aggregated hourly energy loads versus the external temperatures, together with a further analysis of winter peak energy demand under unusually cold weather conditions.

Results revealed that annual gas consumption for the dwellings in this dataset was about four times higher than electricity consumption, while the peak hourly gas to electricity consumption 
ratio was around seven on the coldest days. A correlation between domestic energy consumption in response to changes in external temperatures was quantified through linear regression analysis. Furthermore, the diversity effect in energy consumption among dwellings is discussed with quantitative illustrations regarding how the diversified peak energy demand changes and stabilises when the number of dwellings changes. ADMD curves for both gas and electricity show qualitatively similar asymptotic behaviour, but with significant quantitative differences. The evidence suggests that electricity peak consumption is more diverse than gas peak consumption.

This empirical quantitative analysis of energy loads and demand diversity utilises a large sample of smart meter data from the UK. Methods used in this study are also useful for countries or areas that have cold winters, in order to quantify energy consumption, better understand energy load profiles, and manage peak demand. Analysis of energy demand diversity offers insight to improve energy networks operations, to appropriately size energy generation and distribution infrastructures and capacities, and to reduce costs through economies of scale.

\section{References}

[1] Connolly, D., Heat Roadmap Europe: Quantitative comparison between the electricity, heating, and cooling sectors for different European countries. Energy, 2017. 139: p. 580-593 DOI: https://doi.org/10.1016/j.energy.2017.07.037.

[2] ECUK, Energy consumption in the UK, in Information for overall energy consumption in the UK with details of the transport, domestic, industry and services sectors. 2019: London, UK.

[3] CCC, Net Zero - The UK's contribution to stopping global warming. 2019, The Committee on Climate Change: London, UK.

[4] BEIS, Clean Growth - Transforming Heating. Overview of Current Evidence. 2018, The Department for Business, Energy and Industrial Strategy: London, UK.

[5] CCC, Research on district heating and local approaches to heat decarbonisation. 2016, Committee on Climate Change: London, UK.

[6] Cosic, M., DECC heat networks demonstration SBRI phase 3 report. 2017, COHEAT Ltd.

[7] CIBSE and ADE, Heat networks: Code of Practice for the UK. Raising standards for heat supply. 2015, The Chartered Institution of Building Services Engineers (CIBSE) and the Association for Decentralised Energy (ADE): London, UK.

[8] Spoladore, A., et al., Model for forecasting residential heat demand based on natural gas consumption and energy performance indicators. Applied Energy, 2016. 182: p. 488-499 DOI: https://doi.org/10.1016/j.apenergy.2016.08.122.

[9] Chiu, L.F., et al., A socio-technical approach to post-occupancy evaluation: interactive adaptability in domestic retrofit. Building Research \& Information, 2014. 42(5): p. 574590 DOI: https://doi.org/10.1080/09613218.2014.912539.

[10] Lowe, R., L.F. Chiu, and T. Oreszczyn, Socio-technical case study method in building performance evaluation. Building Research \& Information, 2018. 46(5): p. 469-484 DOI: https://doi.org/10.1080/09613218.2017.1361275.

[11] Chang, R.-F. and C.-N. Lu. Load profiling and its applications in power market. in Power Engineering Society General Meeting, 2003, IEEE. 2003. IEEE DOI: https://doi.org/10.1109/PES.2003.1270442. 
[12] McLoughlin, F., A. Duffy, and M. Conlon, A clustering approach to domestic electricity load profile characterisation using smart metering data. Applied Energy, 2015. 141: p. 190-199 DOI: https://doi.org/10.1016/j.apenergy.2014.12.039.

[13] Sajjad, I.A., G. Chicco, and R. Napoli. A statistical analysis of sampling time and load variations for residential load aggregations. in Multi-Conference on Systems, Signals Devices (SSD). 2014. DOI: https://doi.org/10.1109/SSD.2014.6808851.

[14] Pedersen, L., J. Stang, and R. Ulseth, Load prediction method for heat and electricity demand in buildings for the purpose of planning for mixed energy distribution systems. Energy and Buildings, 2008. 40(7): p. 1124-1134 DOI: https://doi.org/10.1016/j.enbuild.2007.10.014.

[15] Willis, H.L., Spatial electric load forecasting. 2002: CRC Press DOI: https://doi.org/10.1201/9780203910764.

[16] Ziser, C., Z. Dong, and T. Saha. Investigation of weather dependency and load diversity on Queensland electricity demand. in Australasian Universities Power Engineering Conference 2005. 2005. AUPEC 2005.

[17] Psiloglou, B.E., et al., Factors affecting electricity demand in Athens, Greece and London, UK: A comparative assessment. Energy, 2009. 34(11): p. 1855-1863 DOI: https://doi.org/10.1016/j.energy.2009.07.033.

[18] Wan, K.K.W., et al., Impact of climate change on building energy use in different climate zones and mitigation and adaptation implications. Applied Energy, 2012. 97: p. 274-282 DOI: https://doi.org/10.1016/j.apenergy.2011.11.048.

[19] Hong, T., W.-K. Chang, and H.-W. Lin, A fresh look at weather impact on peak electricity demand and energy use of buildings using 30-year actual weather data. Applied Energy, 2013. 111: p. 333-350 DOI: https://doi.org/10.1016/j.apenergy.2013.05.019.

[20] Wilson, G., R. Taylor, and P. Rowley, Challenges for the decarbonisation of heat: local gas demand vs electricity supply Winter 2017/2018. 2018, The UK Energy Research Centre: London, UK.

[21] Good, N., et al., High resolution modelling of multi-energy domestic demand profiles. Applied Energy, 2015. 137: p. 193-210 DOI: https://doi.org/10.1016/j.apenergy.2014.10.028.

[22] Richardson, I., et al., Domestic electricity use: A high-resolution energy demand model. Energy and buildings, 2010. 42(10): p. 1878-1887 DOI: https://doi.org/10.1016/j.enbuild.2010.05.023.

[23] McKenna, R., et al., Analysing socioeconomic diversity and scaling effects on residential electricity load profiles in the context of low carbon technology uptake. Energy Policy, 2016. 97: p. 13-26 DOI: https://doi.org/10.1016/j.enpol.2016.06.042.

[24] Torriti, J., A review of time use models of residential electricity demand. Renewable and Sustainable Energy Reviews, 2014. 37: p. 265-272 DOI: https://doi.org/10.1016/j.rser.2014.05.034.

[25] Bagge, H. and D. Johansson, Measurements of household electricity and domestic hot water use in dwellings and the effect of different monitoring time resolution. Energy, 2011. 36(5): p. 2943-2951 DOI: https://doi.org/10.1016/j.energy.2011.02.037.

[26] Christoph, F., et al., Cluster analysis of smart metering data-an implementation in practice. Business \& Information Systems Engineering, 2012. 4(1): p. 31-39 DOI: https://doi.org/10.1007/s11576-011-0309-8.

[27] Luo, X., et al., Electric load shape benchmarking for small-and medium-sized commercial buildings. Applied energy, 2017. 204: p. 715-725 DOI: https://doi.org/10.1016/j.apenergy.2017.07.108. 
[28] Ramírez-Mendiola, J.L., P. Grünewald, and N. Eyre, The diversity of residential electricity demand-A comparative analysis of metered and simulated data. Energy and Buildings, 2017. 151: p. 121-131 DOI: https://doi.org/10.1016/j.enbuild.2017.06.006.

[29] Yao, R. and K. Steemers, A method of formulating energy load profile for domestic buildings in the UK. Energy and buildings, 2005. 37(6): p. 663-671 DOI: https://doi.org/10.1016/j.enbuild.2004.09.007.

[30] Summerfield, A., et al., Empirical variation in 24-h profiles of delivered power for a sample of UK dwellings: Implications for evaluating energy savings. Energy and Buildings, 2015. 88: p. 193-202 DOI: https://doi.org/10.1016/j.enbuild.2014.11.075.

[31] Bary, C., Coincidence-factor relationships of electric-service-load characteristics. Transactions of the American Institute of Electrical Engineers, 1945. 64(9): p. 623-629 DOI: https://doi.org/10.1109/T-AIEE.1945.5059190.

[32] IEEE, IEEE recommended practice for electric power distribution for industrial plants. Vol. 141. 1994: IEEE Industry Applications Society. Power Systems Engineering Committee.

[33] Boggis, J., Diversity bias and balance. Distribution of Electricity, 1953: p. 357-362.

[34] Barteczko-Hibbert, C., After diversity maximum demand (ADMD) report, in Report for the Customer-Led Network Revolution project. 2015, Durham University.

[35] Seneviratne, A., Information electrical design for distribution networks: After Diversity Maximum Demand. 2013, Horizon Power.

[36] Poursharif, G., Investigating the ability of smart electricity meters to provide accurate low voltage Network information to the UK distribution network operators. 2018, University of Sheffield.

[37] Willis, H.L., Power Distribution Planning Reference Book. 2004 DOI: https://doi.org/10.1201/9781420030310.

[38] Boait, P., V. Advani, and R. Gammon, Estimation of demand diversity and daily demand profile for off-grid electrification in developing countries. Energy for Sustainable Development, 2015. 29: p. 135-141 DOI: https://doi.org/10.1016/j.esd.2015.10.009.

[39] McQueen, D.H., P.R. Hyland, and S.J. Watson, Monte Carlo simulation of residential electricity demand for forecasting maximum demand on distribution networks. IEEE Transactions on power systems, 2004. 19(3): p. 1685-1689 DOI: https://doi.org/10.1109/TPWRS.2004.826800.

[40] McKenna, E. and M. Thomson, High-resolution stochastic integrated thermalelectrical domestic demand model. Applied Energy, 2016. 165: p. 445-461 DOI: https://doi.org/10.1016/j.apenergy.2015.12.089.

[41] Jenkins, D.P., S. Patidar, and S.A. Simpson, Synthesising electrical demand profiles for UK dwellings. Energy and Buildings, 2014. 76: p. 605-614 DOI: https://doi.org/10.1016/j.enbuild.2014.03.012

[42] Elombo, A.I., et al. Residential load variability and diversity at different sampling time and aggregation scales. in AFRICON, 2017 IEEE. 2017. DOI: https://doi.org/10.1109/AFRCON.2017.8095675.

[43] Sun, M., I. Konstantelos, and G. Strbac. Analysis of diversified residential demand in London using smart meter and demographic data. in Power and Energy Society General Meeting (PESGM), 2016. 2016. IEEE DOI: https://doi.org/10.1109/PESGM.2016.7741076.

[44] Summerfield, A.J., et al., Milton Keynes Energy Park revisited: Changes in internal temperatures and energy usage. Energy and Buildings, 2007. 39(7): p. 783-791 DOI: https://doi.org/10.1016/j.enbuild.2007.02.012. 
[45] Love, J., et al., The addition of heat pump electricity load profiles to GB electricity demand: Evidence from a heat pump field trial. Applied Energy, 2017. 204: p. 332-342 DOI: https://doi.org/10.1016/j.apenergy.2017.07.026.

[46] COSTIC, Guide technique pour la mise en oeuvre des modules thermiques d'appartements. 2016, Le COSTIC (Comité Scientifique et Technique des Industries Climatiques), Thermiques d'appartement (MTA).

[47] NAW, DIN 1988-300:2012-05. Code of Practice for drinking water installations - Part 300: Pipe sizing; DVGW code of practice. 2012, The DIN Standards Committee Water Practice (NAW) Häusliche Wasserversorgung: Berlin, Germany.

[48] Dansk Standard, DS439 Norm for vandinstallationer Code of Practice for domestic water supply installations. 2009, Danish Standards Foundation: Copenhagen, Denmark.

[49] SDHA, District heating substations desgin and installation technical requirements. F:101. 2014, Swedish District Heating Association SDHA Stockholm, Sweden.

[50] Hanson-Graville, R., Advances in heat network technology. 2018, Thermal Integration: Suffolk, UK.

[51] CIBSE. Key changes in the updated Heat Networks Code of Practice. 2019 [Accessed: 11th December 2019]; Available from: https://www.cibsejournal.com/uncategorized/key-changes-in-the-latest-heatnetworks-code-of-practice/.

[52] BEIS, Heat meter accuracy testing. 2016, The Department for Business, Energy and Industrial Strategy: London, UK.

[53] Raw, G. and D. Ross, Energy demand research project: Final analysis. 2011, AECOM and Ofgem.

[54] Met Office. Winter 2008/09 and winter 2009/10. 2013 [Accessed: 11th December 2019]; Available from: https://www.metoffice.gov.uk/climate/uk/summaries/2009/winter.

[55] The Guardian. British winter was the coldest for 31 years. Met Office figures recorded a December-to-February mean UK temperature of just 1.51C, while the 1971-2000 average is 3.7C. 2010 [Accessed: 20th July 2019]; Available from: https://www.theguardian.com/uk/2010/mar/02/british-winter-coldest-30-years/.

[56] Prior, J. and M. Kendon, The UK winter of 2009/2010 compared with severe winters of the last 100 years. Weather, 2011. 66(1): p. 4-10 DOI: https://doi.org/10.1002/wea.735.

[57] BEIS, The Clean Growth Strategy in Leading the way to a low carbon future. 2017, The Department for Business, Energy and Industrial Strategy: London, UK.

[58] Met Office, Met Office European Atmospheric Hi-Res Model, in Met Office Unified Model. 2017.

[59] Isaac, M. and D.P. van Vuuren, Modeling global residential sector energy demand for heating and air conditioning in the context of climate change. Energy Policy, 2009. 37(2): p. 507-521 DOI: https://doi.org/10.1016/j.enpol.2008.09.051.

[60] Hitchin, R., C. Pout, and P. Riviere, Assessing the market for air conditioning systems in European buildings. Energy and Buildings, 2013. 58: p. 355-362 DOI: https://doi.org/10.1016/j.enbuild.2012.10.007.

[61] Druckman, A. and T. Jackson, Household energy consumption in the UK: A highly geographically and socio-economically disaggregated model. Energy Policy, 2008. 36(8): p. 3177-3192 DOI: https://doi.org/10.1016/j.enpol.2008.03.021.

[62] Tunzi, M., et al., Improving thermal performance of an existing UK district heat network: A case for temperature optimization. Energy and Buildings, 2018. 158: p. 1576-1585 DOI: https://doi.org/10.1016/j.enbuild.2017.11.049. 
[63] Larminie, F., The history and future of North Sea oil and gas: an environmental perspective. Philosophical Transactions of the Royal Society of London. B, Biological Sciences, 1987. 316(1181): p. 487-493 DOI: https://doi.org/10.1098/rstb.1987.0033.

[64] Ofgem. Understanding trends in energy prices. Office of Gas and Electricity Markets. 2019 [Accessed: 4th December 2019].

[65] Haas, R., et al., The looming revolution: How photovoltaics will change electricity markets in Europe fundamentally. Energy, 2013. 57: p. 38-43 DOI: https://doi.org/10.1016/j.energy.2013.04.034.

[66] Zakeri, B., et al., The direct interconnection of the UK and Nordic power market Impact on social welfare and renewable energy integration. Energy, 2018. 162: p. 11931204 DOI: https://doi.org/10.1016/j.energy.2018.08.019.

[67] Lowe, R. and T. Oreszczyn, Response to the Department for Business, Enterprise \& Regulatory Reform Heat Call for Evidence. 2008.

[68] Sansom, R., Decarbonising low grade heat for low carbon future, in Electrical and Electronic Engineering. 2015, Imperial College London: London, UK.

[69] Element Energy, Hybrid heat pumps study, in A report on the performance and costs of hybrid heat pumps, as well as the potential impact of innovation on these. 2017, Element Energy and the Department for Business, Energy \& Industrial Strategy.

[70] Navarro-Espinosa, A. and P. Mancarella, Probabilistic modeling and assessment of the impact of electric heat pumps on low voltage distribution networks. Applied Energy, 2014. 127: p. 249-266 DOI: https://doi.org/10.1016/j.apenergy.2014.04.026.

\section{Acknowledgements}

This research was made possible by support from the Engineering and Physical Sciences Research Council (EPSRC) Centre for Doctoral Training in Energy Demand (LoLo), [grant numbers EP/L01517X/1 and EP/H009612/1]. The authors gratefully acknowledge EDF Energy R\&D UK Centre Limited for providing smart meter data and financial support, and helpful comments on the research from Marie-Helene Laurent, Benjamin Mousseau and Dominique Bertin. 